\title{
A case report of scrub typhus complicated with myocarditis and rhabdomyolysis
}

\author{
Young-Jae Ki ${ }^{1}$, Dong-Min Kim ${ }^{1 *}$ D, Na-Ra Yoon ${ }^{1}$, Sung-Soo Kim ${ }^{1}$ and Choon-Mee Kim²
}

\begin{abstract}
Background: Scrub typhus is a zoonotic disease caused by Orientia tsutsugamushi, a gram-negative intracellular bacterium. Myocarditis and rhabdomyolysis are rare complications of scrub typhus.

Case presentation: We report a case of scrub typhus, which was simultaneously complicated with myocarditis and rhabdomyolysis. A 54-year-old woman presented to our hospital with myalgia in the upper and lower limbs, oedema and a fever of 7 days' duration. We confirmed the diagnosis of scrub typhus complicated with myocarditis by pericardial fluid analysis and cardiac magnetic resonance imaging results. The pericardial fluid showed characteristics of an exudate, an elevated immunofluorescence assay (IFA) IgG titer of 1:2048 and a positive 16S rRNA qPCR result. We also diagnosed rhabdomyolysis by the patient's presenting symptoms, elevated muscle enzyme levels and bone scan results.
\end{abstract}

Conclusion: We report for the first time a case of scrub typhus complicated with both myocarditis and rhabdomyolysis, the causative agent of which was the Boryong genotype of O. tsutsugamushi.

Keywords: Scrub typhus, Myocarditis, Rhabdomyolysis

\section{Background}

Scrub typhus is a mite-borne infectious disease caused by Orientia tsutsugamushi, a gram-negative intracellular bacterium. This infection is prevalent in rural East Asia and the Western Pacific islands. It is usually characterized by the acute onset of fever, chills, rash, and eschar, and patients can be easily managed by early diagnosis and treatment with doxycycline or tetracycline. However, severe complications such as acute respiratory distress syndrome, meningoencephalitis, pneumonitis, acute renal failure and myocarditis infrequently occur and can be fatal.

To date, cardiac involvement (e.g., myocarditis, pericarditis, and infective endocarditis) or rhabdomyolysis in scrub typhus has been intermittently reported [1-6]. Furthermore, the simultaneous complication of scrub typhus with both myocarditis and rhabdomyolysis has not been reported. Here, we report a case of scrub typhus in a 54-year-old woman presenting with myocarditis and rhabdomyolysis.

\footnotetext{
* Correspondence: drongkim@chosun.ac.kr

${ }^{1}$ Departments of Internal Medicine, College of Medicine, Chosun University,

588 Seosuk-dong, Dong-gu, Gwangju 61453, Republic of Korea

Full list of author information is available at the end of the article
}

\section{Case presentation}

A 54-year-old woman with no previous comorbidity was brought to our Emergency Department for further evaluation of increased levels of muscle enzymes and cardiac enzymes. Prior to admission, she was admitted in a local clinic with myalgia in the upper and lower limbs, oedema and a fever of 7 days' duration. She was diagnosed clinically with scrub typhus by the presence of an eschar in the area of the right shin and was treated with $100 \mathrm{mg}$ doxycycline for 2 days. The occupation of patient was housewife. Upon our physical examination, the blood pressure was $120 / 80 \mathrm{mmHg}$, the pulse rate was 101 beats/min, the respiratory rate was 18 breaths/ min, and the body temperature was $36.7{ }^{\circ} \mathrm{C}$. She was alert and fully oriented. Auscultation of both lungs revealed mild rales in both lower lobes. No heart murmur was audible. The eschar was observed in the area of the right shin.

An electrocardiogram (ECG) performed in the emergency room showed a normal sinus rhythm with a low QRS voltage in all limb leads and precordial leads (Fig. 1a). Chest X-ray revealed a slightly increased cardiothoracic ratio. Laboratory testing showed elevation of the following parameters: white blood cell count $(15,980 / \mu \mathrm{L}$, normal $=$ $4000-10,800 / \mu \mathrm{L})$, erythrocyte sedimentation rate $(35 \mathrm{~mm} /$

(c) The Author(s). 2018 Open Access This article is distributed under the terms of the Creative Commons Attribution 4.0 International License (http://creativecommons.org/licenses/by/4.0/), which permits unrestricted use, distribution, and 

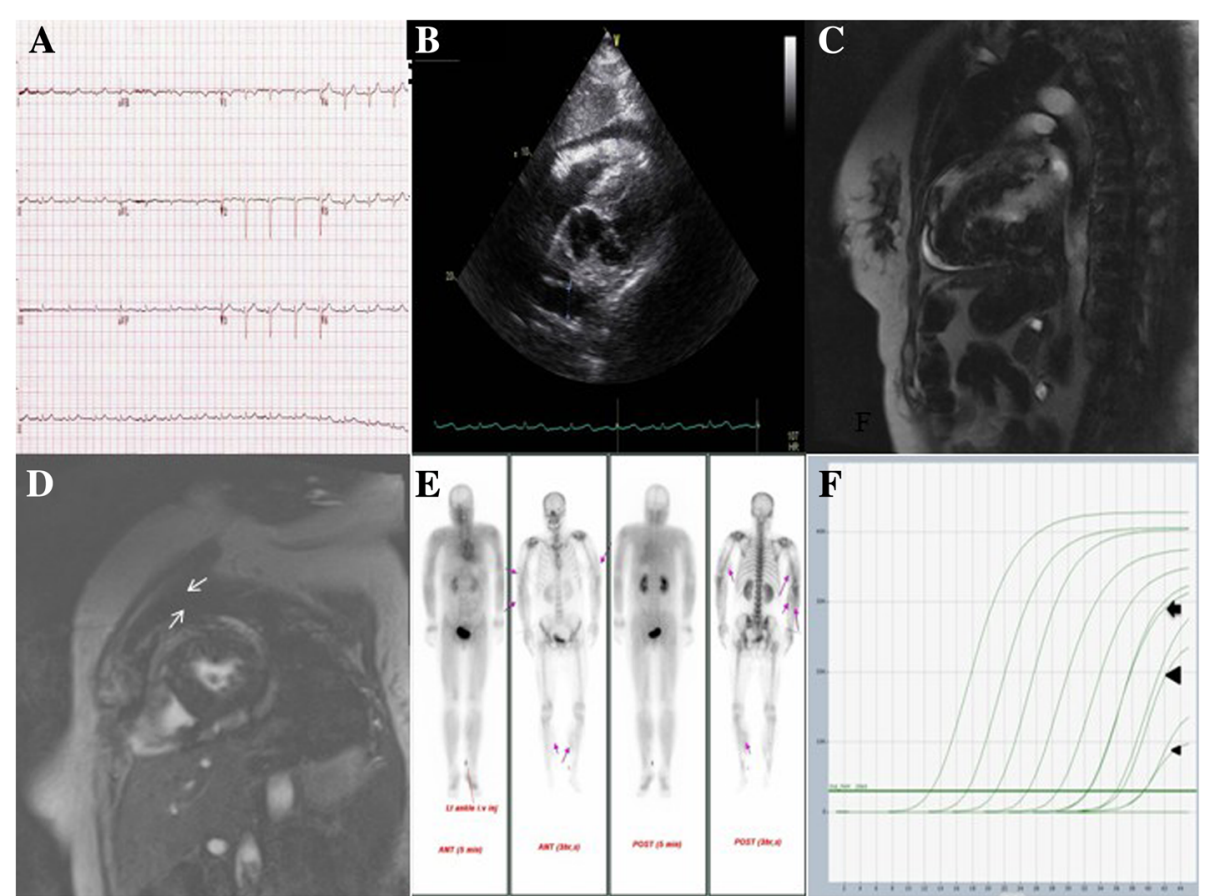

Fig. 1 The electrocardiogram (ECG) performed upon admission showed a normal sinus rhythm with a low QRS voltage in all limb leads and precordial leads (a). The TTE subcostal view revealed a normally sized left ventricle and a mild pericardial effusion (b). Contrast-enhanced cardiac magnetic resonance imaging showed a pericardial effusion and subepicardial enhancement in the apical segment (c). Contrast-enhanced cardiac magnetic resonance imaging showed subepicardial enhancement in the mid anteroseptal and mid anterior segments (d). A bone scan revealed increased soft tissue uptake in both the arms and the legs (e). Real-time PCR targeting the 165 rRNA gene of 0 . tsutsugamushi showed positive at a cross point cycle (Cp) of 32.3 (arrow) in a pericardial fluid specimen, 35.97 (large arrow head) in an eschar specimen, and 39.42 (small arrow head) in an endocardial tissue specimen (positive control: Karp genotype, $\mathrm{Cp}$ value $=19.71)(\mathbf{f})$

hr., normal range $=0-30 \mathrm{~mm} / \mathrm{hr}$ ), C-reactive protein $(2.13 \mathrm{mg} / \mathrm{dL}$, normal $=0-0.3 \mathrm{mg} / \mathrm{dL})$, aspartate aminotransferase $(75.9 \mathrm{IU} / \mathrm{L}$, normal $=10-40 \mathrm{IU} / \mathrm{L})$, creatine phosphokinase $(\mathrm{CPK})(3337 \mathrm{U} / \mathrm{L}$, normal $=55-215 \mathrm{U} / \mathrm{L})$, creatinine kinase-myocardial band (CK-MB) $(104.6 \mathrm{ng} /$ $\mathrm{mL}$, normal $=0-4.88 \mathrm{ng} / \mathrm{mL})$, troponin I $(0.055 \mathrm{ng} / \mathrm{mL}$, normal $=0-0.016 \mathrm{ng} / \mathrm{mL})$, myoglobin $(2498 \mathrm{ng} / \mathrm{mL}$, nor$\mathrm{mal}=25-58 \mathrm{ng} / \mathrm{mL})$, prohormone of brain natriuretic peptide (proBNP) $(477.6 \mathrm{pg} / \mathrm{mL}$, normal $=0-270 \mathrm{pg} / \mathrm{mL})$ and blood urea nitrogen $(36.4 \mathrm{mg} / \mathrm{dL}$, normal $=8.0$ $20 \mathrm{mg} / \mathrm{dL}$ ). Additionally, laboratory testing showed normal levels of creatine $(0.66 \mathrm{mg} / \mathrm{dL}$, normal $=0.5-1.3 \mathrm{mg} /$ $\mathrm{dL})$ and potassium $(4.4 \mathrm{mEq} / \mathrm{L}$, normal $=3.5-5.0 \mathrm{mEq} / \mathrm{L})$ and a decreased level of albumin $(3.07 \mathrm{~g} / \mathrm{dL}$, normal $=$ $3.5-5.2 \mathrm{~g} / \mathrm{dL}$ ). Transthoracic echocardiography (TTE) revealed normal left ventricular systolic function with an ejection fraction of $62 \%$, along with mild pericardial effusion (Fig. 1b).

First of all, scrub typhus with rhabdomyolysis was suspected, administration of intravenous fluid and doxycycline (200 mg/day) was initiated immediately. We confirmed that the serum indirect immunofluorescence assay (IFA) IgM titer against $O$. tsutsugamush $i$ was $<1: 16$ and that the IgG titer was 1:4096. In addition, the nested polymerase chain reaction (PCR) targeting the O. tsutsugamushi $56-\mathrm{kDa}$ protein-encoding gene was negative in a specimen from the blood buffy coat, but positive in an eschar specimen. A comparative analysis of the O. tsutsugamushi DNA sequence obtained from the eschar with sequences in the GenBank database confirmed that the patient was infected with the Boryong genotype [7]. PCR tests to detect Hantavirus, severe fever thrombocytopenia syndrome virus, and species of Anaplasma, Ehrlichia, and Borrelia were all negative [8-11] (Table 1).

During the patient's hospitalization, muscle enzyme and cardiac enzyme levels increased continuously. On day 3 of hospitalization, the creatine phosphokinase level was $18,262 \mathrm{U} / \mathrm{L}$ (normal $=55-215 \mathrm{U} / \mathrm{L}$ ), the CK-MB level was $272.3 \mathrm{ng} / \mathrm{mL}$ (normal $=0-4.88 \mathrm{ng} / \mathrm{mL}$ ), the troponin I level was $1.62 \mathrm{ng} / \mathrm{mL}$ (normal $=0-0.016 \mathrm{ng} /$ $\mathrm{mL}$ ) and the myoglobin level peaked at $3000 \mathrm{ng} / \mathrm{mL}$ (normal $=25-58 \mathrm{ng} / \mathrm{mL}$ ). Despite the lack of specific symptoms, we suspected myocarditis based on the ECG results, TTE imaging findings and the rapid increase in cardiac enzyme levels. Therefore, cardiac magnetic resonance imaging (MRI) was performed. The cardiac MRI demonstrated normal left ventricular function (58.9\%) with a large amount of pericardial effusion. The delayed 
Table 1 Scrub typhus polymerase chain reaction and immunofluorescence assay results by sample collection date

\begin{tabular}{|c|c|c|c|c|c|c|c|c|c|}
\hline \multirow{2}{*}{$\begin{array}{l}\text { Sample collection } \\
\text { date }\end{array}$} & \multirow[t]{2}{*}{ Sample name } & \multicolumn{2}{|l|}{ Scrub typhus PCR } & \multicolumn{2}{|c|}{ Scrub typhus IFA } & \multirow{2}{*}{$\begin{array}{l}\text { HFRS } \\
\text { (RT-N PCR) }\end{array}$} & \multirow{2}{*}{$\begin{array}{l}\text { SFTS } \\
\text { RT-PCR }\end{array}$} & \multirow{2}{*}{$\begin{array}{l}\text { Anaplasma } \\
\text { (groEL) }\end{array}$} & \multirow[t]{2}{*}{ Borrelia } \\
\hline & & 56 kDa kit & $6 \mathrm{~S} q \mathrm{PCR}$ & $\lg M$ & $\lg G$ & & & & \\
\hline \multirow[t]{2}{*}{$2016-11-28^{a}$} & buffy \& plasma & Negative & Negative & $<1: 16$ & 1:4096 & Negative & Negative & Negative & Negative \\
\hline & eschar & Positive (Boryong) & Positive & & & & & Negative & \\
\hline \multirow[t]{2}{*}{$2016-12-02$} & pericardial fluid & Negative & Positive & $<1: 16$ & $1: 2048$ & Negative & & Negative & \\
\hline & tissue (cardiac) & Negative & Positive & & & & & Negative & \\
\hline $2016-12-05$ & buffy \& plasma & & & $<1: 16$ & $1: 2048$ & & & & \\
\hline 2016-12-14 & buffy \& plasma & & & $<1: 16$ & $1: 2048$ & & & & \\
\hline
\end{tabular}

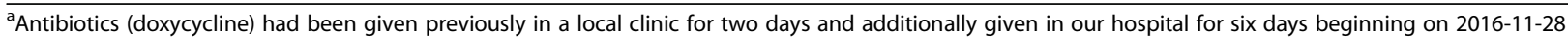

enhancement images revealed a subepicardial enhancement involving the basal lateral, mid anteroseptal, mid anterior and apical segments of the left ventricle wall (Fig. 1c, d).

On day 5 of hospitalization, we performed pericardiocentesis due to the large amount of pericardial effusion without concomitant tamponade physiology, and $195 \mathrm{cc}$ of serous pericardial fluid was aspirated. The pericardial fluid and buffy coat of the patient was inoculated onto L929 cells to isolate the causative microorganisms, but no microorganisms could be isolated. Real-time PCR targeting the $O$. tsutsugamushi $16 \mathrm{~S}$ rRNA gene using a pericardial fluid specimen showed a positive result at a crossing point cycle $(\mathrm{Cp})$ of 32.3 , and $\mathrm{qPCR}$ using an eschar specimen was positive at a $\mathrm{Cp}$ of 35.97 [12] (Fig. 1f). The pericardial fluid analysis showed a white blood cell count of $150 / \mathrm{mm}^{3}$ (80\% monocytes), a total protein level of $4.08 \mathrm{~g} /$ $\mathrm{dL}$, a fluid/serum protein ratio of 0.77 , a lactate dehydrogenase (LDH) level of $764 \mathrm{U} / \mathrm{L}$, and a fluid/serum LDH ratio of 0.65 . By these results, the pericardial fluid was classified as an exudate [13]. The adenosine deaminase level was $21.7 \mathrm{U} / \mathrm{L}$ (normal $=5.8-23 \mathrm{U} / \mathrm{L}$ ), the bacterial and fungal cultures were sterile, and the IFA IgM titer against $O$. tsutsugamushi was $<1: 16$ but the IgG titer was 1:2048 in the pericardial fluid. On the same day, coronary angiography for a differential diagnosis of myocardial infarction revealed no abnormalities. Based on the cardiac MRI results, we performed endomyocardial biopsy (EMB) to evaluate a definite diagnosis of myocarditis. The biopsy specimen consisted of five pieces, which was barely sufficient for real-time PCR, but the pathology report indicated that the specimens contained inadequate tissue for definitive diagnosis. However, we could confirm the diagnosis of scrub typhus myocarditis based on the elevated cardiac enzymes, the pericardial fluid analysis results, and the TTE and cardiac MRI imaging findings. On day of 8 of hospitalization, a follow-up TTE revealed normal left ventricular function with no pericardial effusion.

On day 10 of hospitalization, we also confirmed the diagnosis of rhabdomyolysis from the bone scan, which revealed increased soft tissue uptake in both arms and legs (Fig. 1e). The patient was given continuous intravenous fluid and diuretics for the management of rhabdomyolysis, a 6-day course of doxycycline for the scrub typhus infection and conservative therapy for myocarditis. The patient's renal function and potassium level remained within the normal range throughout the hospitalization. The cardiac enzyme and muscle enzyme levels decreased. On day 16 of hospitalization, the CPK level had decreased to $595 \mathrm{U} / \mathrm{L}$ (normal $=55-215 \mathrm{U} / \mathrm{L}$ ), the CK-MB level was within the normal range at $4.140 \mathrm{ng} / \mathrm{mL}$ (normal $=0$ $4.88 \mathrm{ng} / \mathrm{mL}$ ) and the troponin I level had decreased to $0.096 \mathrm{ng} / \mathrm{mL}$ (normal $=0-0.016 \mathrm{ng} / \mathrm{mL}$ ). The patient was discharged on day 17 of hospitalization after resolution of her presenting symptoms.

\section{Discussion and conclusions}

Myocarditis can present with a wide range of clinical manifestations, from nonspecific symptoms such as fever, myalgia, palpitation and exertional dyspnea to cardiogenic shock or sudden cardiac death [14]. As in our case, the clinical presentation of myocarditis can be deceptive due to the absence of symptoms, and myocarditis should be considered in cases of systemic infection with concomitant new cardiovascular dysfunctions or elevated cardiac enzymes. Myocarditis also mimics myocardial infarction clinically; therefore, coronary artery disease should be included in the differential diagnosis for myocarditis. Viral infections are known to be the most common cause of myocarditis, and many cases of myocarditis caused by the varicella zoster virus, the human immunodeficiency virus and coxsackievirus have been reported $[15,16]$. In comparison, bacterial myocarditis is relatively uncommon [17]. O. tsutsugamushi is primarily localized in the endothelial cells of the heart, lung, brain, kidney, and skin; and within cardiac muscle cells [18]. Subsequently, infection with O. tsutsugamushi results in vasculitis in multiple organs, leading to various complications. Among these complications, cardiac manifestations such as myocarditis, pericarditis and infective endocarditis have been reported [1, 2, 4-6].

EMB results are essential in confirming the diagnosis of myocarditis, but this technique is invasive in haemodynamically unstable patients and also lacks sensitivity 
[14]. Practically, EMB were used to diagnose myocarditis in 111 of 1230 patients (9\%) with unexplained cardiomyopathy in one large study [19]. In addition, only one case of scrub typhus myocarditis has been confirmed by EMB in Japan [20]. In the present case, EMB was performed but we obtained an inadequate specimen amount for definitive diagnosis. However, many researchers have noted strong clinical, ventriculographic, and laboratory evidence of myocarditis among patients with negative biopsies [21, 22]. Recently, cardiac MRI is increasingly being used for the diagnosis and prognostic assessment of myocarditis. In addition, cardiac MRI has three advantages that make it the leading tool for diagnosing myocarditis. First, cardiac MRI enables clinicians to assess cardiac function indirectly. Second, it provides assistance in directing myocardial biopsy to appropriate locations. In comparison with off-target sampling, myocardial biopsy yields improve substantially when combined with cardiac MRI if the sampling is performed in focal regions detected on the cardiac MRI. Lastly, cardiac MRI helps clinicians to differentiate myocarditis from myocardial infarction by the myocardial delayed enhancement pattern [23].

In our case, the patient was administered antibiotics before we obtained her blood sample; therefore, the nested PCR was negative using the buffy coat, but we could confirm scrub typhus by a positive PCR assay using a specimen from the eschar, which is an inoculation site of $O$. tsutsugamushi that presumably contains a high inoculum density. We could also diagnose scrub typhus myocarditis by elevated cardiac biomarker (creatine kinase-MB, cardiac troponin $\mathrm{T}$, and proBNP) levels; positive PCR; elevated IFA IgG titer in pericardial fluid; and noninvasive test results such as ECG, echocardiography and cardiac MRI.

To our knowledge, this is the first case of scrub typhus myocarditis with the Boryong genotype genetically confirmed as the causative agent. In addition, we performed pericardial fluid analysis for the first time in a scrub typhus patient with myocarditis or pericarditis. The pericardial effusion had characteristics of an exudate and was PCR-positive for O. tsutsugamushi $16 \mathrm{~S}$ rRNA. Taken together, we can assume that scrub typhus myocarditis occurred by direct invasion of O. tsutsugamushi [12]. Further study is needed to elucidate the mechanisms contributing to myocarditis due to O. tsutsugamushi.

Rhabdomyolysis is caused by tissue hypoxia, metabolic abnormality, toxin release and bacterial invasion. Rhabdomyolysis caused by bacterial infection has been reported occasionally but there have been only 2 case reports about rhabdomyolysis associated with scrub typhus [3, 24]. Clinical manifestations of rhabdomyolysis present as myalgia, general weakness, dark-coloured urine and acute renal failure. Our patient presented with myalgia in both upper and lower limbs and elevated levels of serum CPK and myoglobin, and the diagnosis was ultimately confirmed from a bone scan. The proposed mechanism leading to rhabdomyolysis in scrub typhus is the same as for myocarditis and other vasculitic complications. Cardiac enzyme levels are a very useful tool for diagnosing myocardial injury but can be falsely elevated in rhabdomyolysis.

The treatment strategy for rhabdomyolysis and myocarditis is different; for example, intravenous hydration is beneficial for prevention of acute kidney injury in rhabdomyolysis but can be harmful in myocarditis with depressed left ventricular function. Although myocarditis and rhabdomyolysis are rare complications of scrub typhus individually, both complications can occur together, as in our case. Therefore, a careful workup should be considered for scrub typhus patients with elevated cardiac enzymes to determine whether the elevated levels originate from ischaemic conditions or myocarditis or are falsely elevated due to rhabdomyolysis.

Our case report includes two limitations. First, no microorganism was cultured from either the pericardial fluid or the buffy coat, possibly due to the early administration of antibiotics. Second, although we performed EMB, we obtained an inadequate sample amount for definitive diagnosis of myocarditis.

Here, we reported a case of scrub typhus caused by the Boryong genotype of $O$. tsutsugamushi, which was complicated with both myocarditis and rhabdomyolysis for the first time. Analysis of the pericardial fluid showed that the pericardial effusion had characteristics of an exudate, a high IgG IFA antibody titer and a positive qPCR result for O. tsutsugamushi $16 \mathrm{~S}$ rRNA.

\section{Abbreviations}

CK-MB: Creatinine kinase-myocardial band; Cp: Crossing points; CPK: Creatine phosphate kinase; ECG: Electrocardiogram; EMB: Endomyocardial biopsy; IFA: Immunofluorescence assay; LDH: Lactate dehydrogenase; MRI: Magnetic resonance imaging; PCR: Polymerase chain reaction; ProBNP: Prohormone of brain natriuretic peptide; TTE: Transthoracic echocardiography

\section{Acknowledgements}

Not applicable.

\section{Funding}

This research did not receive any specific grant from funding agencies in the public, commercial, or not-for-profit sectors.

Availability of data and materials

All data generated or analysed during this study are included in this published article.

\section{Authors' contributions}

DMK designed and coordinated the study and contributed to drafting and reviewing the manuscript during the course of submission. YJK collected the patient's clinical data and pathologic data, wrote the manuscript, and revised the draft during the course of submission. CMK carried out the molecular analysis and immunofluorescence assay, wrote the manuscript, and also revised the draft during the course of submission. NRY and SSK were directly responsible for the patient and performed the clinical examinations and helped to draft the manuscript. All the authors read and approved the final version of manuscript. 


\section{Ethics approval and consent to participate}

Not applicable.

\section{Consent for publication}

Written informed consent was obtained from the patient for the publication of this case report and any accompanying images. A copy of the written consent is available for review by the Editor of this journal.

\section{Competing interests}

The authors declare that they have no competing interests.

\section{Publisher's Note}

Springer Nature remains neutral with regard to jurisdictional claims in published maps and institutional affiliations.

\section{Author details}

'Departments of Internal Medicine, College of Medicine, Chosun University, 588 Seosuk-dong, Dong-gu, Gwangju 61453, Republic of Korea. ${ }^{2}$ Premedical Science, College of Medicine, Chosun University, Gwangju, Republic of Korea.

Received: 21 June 2018 Accepted: 23 October 2018

\section{Published online: 07 November 2018}

\section{References}

1. Chang JH, Ju MS, Chang JE, Park YS, Han WS, Kim IS, Chang WH. Pericarditis due to Tsutsugamushi disease. Scand J Infect Dis. 2000;32(1):101-2.

2. Sittiwangkul R, Pongprot $Y$, Silviliarat $S$, Oberdorfer $P$, Jittamala $P$, Sirisanthana $\checkmark$. Acute fulminant myocarditis in scrub typhus. Ann Trop Paediatr. 2008:28(2):149-54

3. Kumar BA, Kumar AS, Sharvanan E. Rhabdomyolysis in scrub typhus: an unusual presentation. Int J Prev Med. 2013;4(12):1472-5.

4. Yu S, Yu X, Zhou B, Liu D, Wang M, Zhang H, Qian X. Tsutsugamushi disease presenting with aortic valve endocarditis: a case report and literature review. Am J Cardiovasc Dis. 2016;6(4):185-90.

5. Jung YH, Lee M, Lee KH, Lee JH, Kim S-h, Lee BK. Acute fulminant myocarditis recovered from electro-mechanical dissociation in scrub typhus. Ewha Med J. 2016;39(1):1-5

6. Ognibene AJ, O'Leary DS, Czarnecki SW, Flannery EP, Grove RB. Myocarditis and disseminated intravascular coagulation in scrub typhus. Am J Med Sci. 1971:262(4):233-9.

7. Jang MS, Kim CM, Kim DM, Yoon NR, Han MA, Kim HK, Oh WS, Yoon HJ, Wie SH, Hur J. Comparison of preferred bite sites between mites and ticks on humans in Korea. Am J Trop Med Hyg. 2016:95(5):1021-5.

8. Klempa B, Fichet-Calvet E, Lecompte E, Auste B, Aniskin V, Meisel H, Denys C, Koivogui L, ter Meulen J, Kruger DH. Hantavirus in African wood mouse, Guinea. Emerg Infect Dis. 2006;12(5):838-40.

9. Roux V, Fournier PE, Raoult D. Differentiation of spotted fever group rickettsiae by sequencing and analysis of restriction fragment length polymorphism of PCR-amplified DNA of the gene encoding the protein rOmpA. J Clin Microbiol. 1996;34(9):2058-65.

10. Tabara K, Arai S, Kawabuchi T, Itagaki A, Ishihara C, Satoh H, Okabe N, Tsuji M. Molecular survey of Babesia microti, Ehrlichia species and Candidatus neoehrlichia mikurensis in wild rodents from Shimane prefecture, Japan. Microbiol Immunol. 2007:51(4):359-67.

11. Yun SM, Lee WG, Ryou J, Yang SC, Park SW, Roh JY, Lee YJ, Park C, Han MG. Severe fever with thrombocytopenia syndrome virus in ticks collected from humans, South Korea, 2013. Emerg Infect Dis. 2014;20(8):1358-61.

12. Kim CM, Cho MK, Kim DM, Yun NR, Kim SW, Jang SJ, Ahn YJ, Lim D. Accuracy of conventional PCR targeting the 16S rRNA gene with the Ot-16sRF1 and Ot-16sRR1 primers for diagnosis of scrub typhus: a case-control study. J Clin Microbiol. 2016;54(1):178-9.

13. Meyers DG, Meyers RE, Prendergast TW. The usefulness of diagnostic tests on pericardial fluid. Chest. 1997;111(5):1213-21.

14. Magnani JW, Dec GW. Myocarditis: current trends in diagnosis and treatment. Circulation. 2006:113(6):876-90

15. Chrysohoou C, Tsiamis E, Brili S, Barbetseas J, Stefanadis C. Acute myocarditis from coxsackie infection, mimicking subendocardial ischaemia. Hellenic $J$ Cardiol. 2009;50(2):147-50

16. Donoiu I, Istratoaie $\mathrm{O}$, Varicella-zoster myocarditis mimicking acute myocardial infarction. Curr Health Sci J. 2014;40(1):78-80.
17. Haddad F, Berry G, Doyle RL, Martineau P, Leung TK, Racine N. Active bacterial myocarditis: a case report and review of the literature. J Heart Lung Transplant. 2007;26(7):745-9.

18. Moron CG, Popov VL, Feng HM, Wear D, Walker DH. Identification of the target cells of Orientia tsutsugamushi in human cases of scrub typhus. Mod Pathol. 2001;14(8):752-9.

19. Felker GM, Thompson RE, Hare JM, Hruban RH, Clemetson DE, Howard DL, Baughman KL, Kasper EK. Underlying causes and long-term survival in patients with initially unexplained cardiomyopathy. N Engl J Med. 2000; 342(15):1077-84.

20. Yotsukura M, Aoki N, Fukuzumi N, Ishikawa K. Review of a case of tsutsugamushi disease showing myocarditis and confirmation of rickettsia by endomyocardial biopsy. Jpn Circ J. 1991;55(2):149-53.

21. Dec GW Jr, Palacios IF, Fallon JT, Aretz HT, Mills J, Lee DC, Johnson RA. Active myocarditis in the spectrum of acute dilated cardiomyopathies: clinical features, histologic correlates, and clinical outcome. N Engl J Med. 1985;312(14):885-90.

22. Herskowitz A, Campbell S, Deckers J, Kasper EK, Boehmer J, Hadian D, Neumann DA, Baughman KL. Demographic features and prevalence of idiopathic myocarditis in patients undergoing endomyocardial biopsy. Am J Cardiol. 1993;71(11):982-6.

23. Olimulder MA, van Es J, Galjee MA. The importance of cardiac MRI as a diagnostic tool in viral myocarditis-induced cardiomyopathy. Neth Heart J. 2009:17(12):481-6.

24. Young PC, Hae CC, Lee KH, Hoon CJ. Tsutsugamushi infection-associated acute rhabdomyolysis and acute renal failure. Korean J Intern Med. 2003: 18(4):248-50.

\section{Ready to submit your research? Choose BMC and benefit from:}

- fast, convenient online submission

- thorough peer review by experienced researchers in your field

- rapid publication on acceptance

- support for research data, including large and complex data types

- gold Open Access which fosters wider collaboration and increased citations

- maximum visibility for your research: over $100 \mathrm{M}$ website views per year

At BMC, research is always in progress.

Learn more biomedcentral.com/submission 